\title{
El francés en Europa y en la Unión Europea: auge y caída de una lengua franca
}

\author{
David FERNÁNDEZ VÍTORES \\ Centro de Estudios Superiores Felipe II (Universidad Complutense de Madrid) \\ Facultad de Traducción e Interpretación \\ david.fernandez@ajz.ucm.es
}

Recibido: 30 de octubre de 2009

Aceptado: 17 de marzo de 2009

RESUMEN

El presente artículo analiza las causas de la pérdida de la posición privilegiada que ocupaba el francés en Europa y en la Unión Europea antes de la entrada de Reino Unido en la UE. Con tal finalidad, el artículo describe, en primer lugar, los factores históricos que hicieron de esta lengua uno de los principales instrumentos de comunicación internacional del viejo continente. Posteriormente, localiza el origen de su actual declive y estudia las estrategias de defensa adoptadas por las autoridades galas para frenar la estampida que se estaba produciendo por parte de los hablantes hacia la utilización del inglés como lengua de comunicación supranacional en el ámbito institucional y extrainstitucional de la UE. Por último, valora someramente los resultados de dicha estrategia.

Palabras clave: lengua franca, Unión Europea, diversidad lingüística, Tratado de Maastricht.

\section{Le français en Europe et l'Union européenne: l'essor et la chute d'une lingua franca}

\section{RÉSUMÉ}

Cet article se propose d'analyser les causes qui ont amené la langue Française à perdre la position privilégiée qu'elle occupait en Europe et dans l'Union Européenne avant l'entrée du Royaume-Uni dans l'UE. Dans ce but, l'article décrit tout d'abord les facteurs historiques qui avaient fait de cette langue l'un des principaux instruments de communication internationale dans le vieux continent. Il analyse par la suite l'origine du déclin actuel du Français, et il étudie les diverses stratégies de défense adoptées par les autorités françaises pour arrêter la fuite déjà initiée des natifs des différentes langues vers un usage de l'Anglais comme langue de communication supranationale dans un domaine tant institutionnel qu'extra-institutionnel de l'UE. Finalement, l'article propose une évaluation sommaire des résultats de ces stratégies.

Mots clés: lingua franca, Union européenne, diversité linguistique, Traité de Maastricht.

\section{The French in Europe and the European Union: the rise and fall of a lingua franca}

\begin{abstract}
This paper analyzes why the French language has lost the privileged position it once held in the European Union before the entry of the United Kingdom. Firstly, the article describes the historical factors that had made French one of the major tools for international communication in the old continent.
\end{abstract}


Then, the paper locates the origin of its current decline, and examines the defensive strategies adopted by French authorities to stop the stampede that was taking place towards the use of English as a supranational language for communication at institutional and extra-institutional levels in the EU. Finally, the paper briefly assesses the outcome of these strategies.

Key words: lingua franca, European Union, linguistic diversity, Maastricht Treaty.

Sumario: 1. Nacimiento y consolidación del francés como lengua franca europea. 2. El francés en la Unión Europea. 3. La pérdida de la posición de lengua franca privilegiada. 4. La diversidad lingüística como instrumento de defensa del francés. 5. Conclusiones.

\section{Nacimiento y consolidación del francés como lengua franca europea.}

Antes de adentrarnos en el análisis de la posición del francés en Europa, conviene señalar que admitimos que existen fenómenos extralingüísticos que pueden favorecer la utilización de una lengua determinada fuera del grupo de sus hablantes nativos y, de esta manera, acabar trasformándola en una lengua franca. En este sentido, compartimos con Wright (2004: 118) la existencia de una relación de causalidad entre el ámbito político y el social en lo que se refiere al desarrollo de las lenguas como instrumentos de comunicación entre grupos de hablantes nativos de diferentes idiomas. Aclarado, pues, este punto, pasamos a considerar los factores que contribuyeron a consolidar el francés como lengua franca mundial para adentrarnos, más adelante, en el estudio de estos factores en el caso concreto de Europa y la Unión Europea.

Así, los factores que influyeron en el establecimiento del francés como lengua franca europea están estrechamente ligados a la posición dominante de Francia en Europa. Por eso, como ha indicado Hàgene (1987: 157) la universalidad del francés se sitúa entre finales del siglo XVII y el penúltimo cuarto del siglo XIX, que coincide con el período de hegemonía económica y cultural francesa en el mundo.

En primer lugar, Francia era una potencia militar de primer orden con una política de expansión territorial que abarcó varios siglos. De hecho, desde el final de la guerra de los Cien Años - 1435 - hasta el final de la guerra franco-prusiana 1870-1871-, en la que Francia perdió los territorios de Alsacia y Lorena (Sánchez Andrés 2003: 166), su territorio nacional no hizo más que incrementarse. Ya fuera a través de descendientes directos o no, la familia real francesa supo garantizar su sucesión de forma continuada desde el siglo X hasta el XVIII, lo que convirtió a esta dinastía en la más estable de Europa. De esta forma, a medida que los miembros de la realeza francesa se casaban con miembros de otras casas reales, el francés fue extendiéndose entre las élites europeas (Wright 2004: 118).

El reinado de Luis XIV supuso el apogeo de la política expansionista francesa y trajo consigo la incursión de Francia en los territorios situados más allá del Rin y de los Pirineos. Como prueba de la hegemonía francesa, el monarca insistió en que los Tratados de Nijmegen - 1678 y 1679- se negociaran en francés y no en latín, como era costumbre. Es más, el texto del Tratado de Rastadt — de 6 de marzo de 
1714 - en virtud del cual el monarca francés cesaba en su intento de conseguir el trono español, poniéndose de esta forma fin a la guerra de Sucesión española, fue redactado en francés. Algo que no deja de resultar curioso, puesto que se trataba de una devolución de territorios al emperador Carlos VI (Hàgene 1996) ${ }^{1}$. Así, el francés fue imponiéndose poco a poco como lengua de la diplomacia. Esta posición privilegiada fue casi incontestable hasta comienzos del siglo XX. El inicio del declive de esta lengua en la esfera diplomática coincide en el tiempo con el inicio del ascenso del inglés como lengua de la diplomacia. Este punto de inflexión fue la aparición del inglés, al lado del francés, en el Tratado que puso fin a la Primera Guerra Mundial (Cohen 1973: 313).

En segundo lugar, Francia también era una gran potencia económica. Sin contar a Rusia, el país galo era el Estado más grande de Europa en la Edad Moderna tanto por su número de habitantes (Braudel 1986) como por su extensión. Tanto es así que, en vísperas de la revolución francesa, uno de cada cinco habitantes europeos era francés (Hobsbawm 1987: 105). Aunque el crecimiento demográfico nacional se ralentizó considerablemente en el siglo XIX, el poderío político y económico francés se extendía ya por los cinco continentes (Wright 2004: 119). El comercio con sus vecinos europeos fue muy importante y, como es lógico, tuvo consecuencias que afectaron al uso del francés como herramienta de comunicación transnacional (Wright 2006: 37). Asimismo, el número de francófonos aumentó en el interior del país cuando la escolarización se hizo obligatoria para todos. En cuanto a los territorios de ultramar, es cierto que no todos los súbditos de las colonias dominaban la lengua de la metrópoli, pero en todas las colonias existía una pequeña élite que había sido educada utilizando como instrumento la lengua del imperio. Además, en algunas de estas colonias, un amplio porcentaje de la mano de obra empleada utilizaba lenguas pidgin o criollas basadas en el francés. Es decir, hubo una penetración vertical - de arriba abajo - de la lengua entre los grupos colonizados que adquirió carta de naturaleza con la introducción de este idioma como lengua de la enseñanza (ibídem). De esta forma, a medida que el comercio y la colonización francesas fueron cobrando impulso a lo largo de los siglos, se incrementó la necesidad de utilizar esta lengua como instrumento de comunicación en los principales emporios comerciales e industriales (Wright 2004: 119). A esta consolidación del francés en los centros de negocios contribuyó sin duda la fuerte expansión comercial de Francia, que, durante la segunda mitad del siglo XVIII puede describirse como espectacular, y que hizo que ciudades como El Havre y Marsella adquirieran un papel cada vez más relevante (Ogg 1987: 84).

En tercer lugar, durante varios siglos, París fue el principal foco cultural mundial. A lo largo del siglo XVII, Luis XIII y Luis XIV se ocuparon de convertir a París en el centro de la vida aristocrática francesa (Fumaroli 2001). El mecenazgo

\footnotetext{
${ }^{1}$ Según los acuerdos alcanzados, las hasta entonces posesiones españolas en los Países Bajos y en Italia - Nápoles, Milanesado, presidios de Toscana y Cerdeña—, así como las posesiones al este del río Rin arrebatadas por los franceses, pasaban a formar parte de los territorios de la Casa de Habsburgo - Sacro Imperio-. Por otra parte, Alsacia y Estrasburgo hacían lo propio con respecto al reino de Francia.
} 
de las artes, que, en principio, era un medio para aumentar el prestigio de la monarquía entre la nobleza, tuvo gran influencia fuera de las fronteras francesas. A finales del siglo XVI, las cortes de Berlín, Hannover, Dresde, Kassel, Darmstadt, Stuttgart, Munich y Viena, que eran además los núcleos de la vida intelectual y política del mundo germanófono de la época, comenzaron a incorporar aspectos de la cultura francesa y a utilizar el francés como herramienta de comunicación hasta el punto de jactarse los cortesanos de hablar como en Versalles (Bruneau 1966 (b) : 100). De hecho, a finales del siglo XVIII, el "afrancesamiento" de las clases aristocráticas alemanas era un hecho (ibídem). Además, el francés comenzó a sustituir al latín como lengua académica, garantizando así el acceso a las fuentes del conocimiento a un público internacional más amplio (Wright 2004: 119). Como ha indicado Bruneau (1966 (a) : 271), la época de la Ilustración vio el nacimiento de un nuevo tipo de intelectual europeo que comprendía, hablaba y hasta pensaba en francés. Con todo, a partir de la derrota de Francia a manos de Prusia en 1870, muchos comenzaron a dudar de la supremacía cultural y diplomática del país galo (Holt 2002: 104).

En cuarto lugar, los franceses representaron un papel pionero en el ámbito científico. No fueron pocos los científicos franceses, como Lavoisier, D'Aubenton, Condillac, D'Alembert, Coulomb o De Lagrange, que, junto con sus ideas, exportaron también la importancia del francés en el ámbito internacional. En el campo de la innovación técnica ocurrió algo parecido. Al menos así se desprende de las aplicaciones técnicas introducidas por los hermanos Montgolfier, Appert o Conté (Wright 2006: 38). De hecho, los 17 tomos de la Enciclopedia, que intentaron ser un compendio de todas las áreas del conocimiento humano, dan fe de la primacía de la influencia francesa durante todo el período de la Ilustración (Wright 2004: 120). Durante el siglo XIX, la necesidad de los científicos no franceses de consultar los trabajos de Niepce y Daguerre, Ampère, Pasteur, los hermanos Lumière, Ader, Bequerel y el matrimonio Curie siguió siendo un acicate para el aprendizaje del francés (Wright 2006: 38).

En quinto lugar, el mundo francófono fue un importante caldo de cultivo para la aparición de nuevas ideas filosóficas y políticas que moldearon ideológicamente la era moderna. Las obras de autores como Montesquieu, Voltaire o Rousseau trascendieron las fronteras nacionales y exportaron conceptos tales como el de "pueblo soberano" o "gobierno democrático" (ibídem). Después de la Revolución francesa de 1789, la primacía ideológica de Francia fue todavía más patente. Como ha indicado Hobsbawm (1987: 104), Francia proporcionó el vocabulario y los programas de los partidos liberales, radicales y democráticos de la mayor parte del mundo y definió empíricamente el concepto y el vocabulario del nacionalismo. Además, los códigos legales franceses servirían de modelo para la codificación legal en otros países, lo que explica en parte la importancia actual del francés en el ámbito jurídico, especialmente en el europeo.

Efectivamente, antes de la Revolución francesa el uso del francés se había extendido, pero únicamente entre las élites aristocráticas. En el siglo XIX, favorecido en gran parte por la rapidez de las comunicaciones, el conocimiento de lenguas extranjeras entre las personas cultas, los sabios, los técnicos y los comerciantes se convirtió en un requisito casi indispensable. Esto hizo que la enseñanza de los 
idiomas se introdujera en el ámbito educativo tanto público como privado, lo que provocó una cierta división entre lenguas de utilidad y lenguas de la cultura (Bruneau 1966 (b) : 101). Esto propició que, el francés, que era la lengua de utilidad para los vecinos inmediatos de Francia, se convirtiera en todo el mundo en una lengua de la cultura (ibídem).

Por último, el francés también fue importante en el ámbito religioso. Ginebra, la ciudad en la que Calvino se estableció en 1536, y que adoptó y divulgó la doctrina calvinista, era mayoritariamente francófona. Por otra parte, el Edicto de Nantes ${ }^{2}$, que, en principio, intentaba solucionar el conflicto religioso entre católicos y protestantes (Saint-Prosper 1840: 436), supuso, tras su revocación, el éxodo masivo de los hugonotes, debilitando, con ello, la economía francesa (De Bertier de Sauvigny et ál. 1986: 229), pero fortaleciendo la posición de la lengua francesa en los países protestantes que los acogieron - Inglaterra, Alemania, Suiza, Países Bajos-, así como en sus colonias.

El análisis histórico sugiere que la consolidación del francés como lengua franca de Europa no se debe a las cualidades intrínsecas de la lengua, a pesar de los esfuerzos de Rivarol en 1783 por demostrar lo contrario en su famoso Discours sur l'universalité de la langue française (Hagene 1987: 164). Cualidades que, en ocasiones, aún esgrime la Academia de la Lengua Francesa en la actualidad (Carrère D'Encausse 2002: 1) para defender el uso del francés frente al de otros idiomas como lengua franca internacional. Como ha indicado Wright (2004: 121-122), la expansión de este idioma no se debió a una promoción de la lengua como tal por parte de los hablantes franceses. Su aprendizaje y uso se debían, más bien, a que los hablantes de este idioma tenían una fuerte influencia política, económica y cultural. Desde este punto de vista, la expansión de la lengua puede considerarse un efecto secundario de esta influencia más que una política de promoción de la lengua propiamente dicha.

\section{El francés en la Unión Europea.}

El estudio de la evolución histórica de la lengua francesa describe una situación de dominio y expansión de este idioma en la escena europea que es casi la antítesis de la situación actual de esta lengua en el ámbito de la Unión Europea. De hecho, desde la entrada en la UE de Reino Unido e Irlanda en 1973, el francés no ha dejado

\footnotetext{
${ }^{2}$ Firmado el 13 de abril de 1598 por el rey Enrique IV de Francia, el edicto de Nantes tenía por objeto lograr la coexistencia pacífica de dos confesiones, la católica y la protestante, con los mismos derechos, en el seno de un Estado católico. Se hicieron muchas concesiones a los protestantes, que, además de tener reconocida la libertad de conciencia, gozaban de libertad de culto (De Bertier de Sauvigny et ál. 1986: 175). Sin embargo, a partir del año 1660, Luis XIV emprendió una política de conversión de los protestantes al catolicismo en todo el reino de Francia. Política que culminó con la revocación del texto religioso del edicto de Nantes por Luis XIV el 18 de octubre de 1685 mediante otro nuevo edicto, el de Fontainebleau. De esta manera, el protestantismo fue prohibido en todo el territorio francés. Se calcula que, aproximadamente, fueron entre 200.000 y 300.000 los exiliados, entre los que se contaban intelectuales, artistas y miembros de la burguesía, lo que debilitó la posición de Francia como punto de referencia en el mundo (ibídem: 229).
} 
de perder el terreno conquistado históricamente. Las razones de esta pérdida de protagonismo probablemente sean las mismas que propiciaron su implantación como lengua franca Europea, pero a la inversa. En otras palabras, del mismo modo que, en el pasado, el poderío francés en el terreno político, económico, cultural, ideológico y tecnológico hizo del francés una herramienta necesaria para la comunicación internacional, la pérdida de protagonismo de Francia en estos terrenos ha acarreado también una disminución en el uso de este idioma como lengua franca mundial (Wright 2006: 38), especialmente en Europa.

La constitución de la Comunidad Europea en 1958 supuso un fuerte estímulo para el afianzamiento del francés en Europa, sobre todo en el ámbito institucional. Además, el hecho de que hasta 1973 no se introdujera el inglés como lengua oficial de la UE favoreció la influencia del francés en casi todos los niveles comunicativos institucionales de la Unión (Longman 2007: 192). A esta influencia contribuyó sin duda el papel secundario desempeñado por Alemania en el plano político (Phillipson 2003: 126). Este papel preponderante del francés como lengua franca de la Unión ha ido debilitándose gradualmente a favor del inglés hasta la firma del Tratado de Maastricht en 1992, fecha en la que la posición de las dos lenguas estaba bastante igualada en el seno de la UE, aunque el reparto de fuerzas de ambos idiomas estaba ubicado en ámbitos diferentes: intrainstitucional en el caso del francés y extrainstitucional y social en el caso del inglés.

Como ha sugerido Truchot (2001: 26), esta situación de dominio del francés durante más de 30 años es un fenómeno único en la comunicación internacional contemporánea: no existe otro caso de una lengua que, en una situación de mercado lingüístico, haya conseguido imponerse al inglés. Las razones que normalmente se aducen para explicar este hecho son que el francés es la lengua más común entre los seis países fundadores de la Comunidad, que Reino Unido no formaba parte de ese grupo de seis países y que las principales instituciones comunitarias estaban situadas en Bruselas y Luxemburgo.

Con todo, hay algunos factores relativos a las decisiones políticas adoptadas y las prácticas institucionales asentadas en la evolución de la Unión Europea que, a pesar del fuerte avance del inglés en cuanto al número de hablantes institucionales y extrainstitucionales, han contribuido a configurar el actual bastión institucional en lo que al uso del francés se refiere y, por tanto, a favorecer su influencia sobre el resto de las lenguas oficiales de la Unión. Entre otros, Phillipson (2003: 125-6) enumera los siguientes:

1. En los años anteriores a la constitución de la CEE en 1958, el Gobierno de Francia hizo todo lo posible para que el francés se estableciera como única lengua oficial de las entonces embrionarias instituciones de la Comunidad. Sin embargo, la fuerte oposición de los alemanes y los holandeses obligó al país galo a admitir el principio de igualdad lingüística. 
2. La cultura administrativa francesa resulta evidente en la traducción del acervo comunitario $^{3}$ : aunque existan equivalentes de traducción en otras lenguas, el término francés sigue siendo el de referencia.

3. En la página web del Tribunal de Justicia de la Unión Europea, los tipos de casos de los que puede entender esta institución se especifican en todas las lenguas oficiales. Sin embargo, se proporciona el término francés junto con sus equivalentes en otros idiomas dando a entender que, de no ser así, resultarían incomprensibles, porque estos términos han surgido de la cultura legal francesa. De hecho, el francés tiene un estatus privilegiado en el Tribunal de Justicia.

4. Cuando a principios de los años noventa, Finlandia se estaba preparando para su entrada en el club europeo y tenía que realizar la traducción de las más de 150.000 páginas correspondientes a las directivas comunitarias, se escogió para la traducción la versión inglesa de las mismas. Sin embargo, los finlandeses se vieron obligados a cambiar a la versión francesa, porque las fuentes en inglés presentaban problemas de fiabilidad e interpretación.

5. La resolución del Consejo de la Unión de 14 de febrero de 2002 relativa a la promoción de la diversidad lingüística y el aprendizaje de lenguas en el marco de la realización de los objetivos del Año Europeo de las Lenguas 2001 tiene un estilo burocrático marcadamente francés ${ }^{4}$.

6. La obligación de los traductores de conservar la misma estructura de frase en todas las lenguas favorece la uniformidad entre las versiones en los distintos idiomas. Sin embargo, esta obligación muchas veces va en contra de las normas que favorecen una redacción clara e inteligible en otras tradiciones legales. Al ser el francés la lengua de referencia, la estructura retórica de esta lengua se ha transferido a las versiones realizadas en otros idiomas o los ha contaminado. A pesar de los esfuerzos de los traductores por hacer que sus traducciones sean lo más cercanas posible a su lengua meta, es probable que estas estructuras influyan en su trabajo de forma inconsciente.

En resumen, puede decirse que tanto la evolución histórica del francés como la inercia creada por los procesos institucionales consolidados en los primeros años de andadura de la Comunidad Económica Europea han favorecido la posición privilegiada de la lengua francesa en las instituciones comunitarias. Sin embargo, a principios de los noventa, esta situación de privilegio se veía amenazada por el imparable avance del inglés.

\section{La pérdida de la posición de lengua franca privilegiada.}

Varios son los elementos que indicaban la pérdida de la posición privilegiada que ocupaba la lengua francesa en el ámbito institucional de la UE en relación con sus dos competidores inmediatos: el inglés y el alemán. Si, como sugiere Truchot

\footnotetext{
${ }^{3}$ De hecho, es frecuente utilizar el término francés Acquis Communautaire para referirse al acervo comunitario.

${ }^{4}$ Véase Diario Oficial de las Comunidades Europeas n. ${ }^{\circ} \mathrm{C}$ 50/1 de 23 febrero de 2002.
} 
(2003: 104) tomamos como referencia los textos primarios — aquellos textos iniciales que constituyen la base para las traducciones posteriores al resto de lenguas oficiales - redactados en cada una de las tres lenguas francas en liza en la Comisión Europea para determinar cuál era el reparto de fuerzas entre las distintas lenguas, los datos que obtenemos son los siguientes:

GRÁFICO 1.

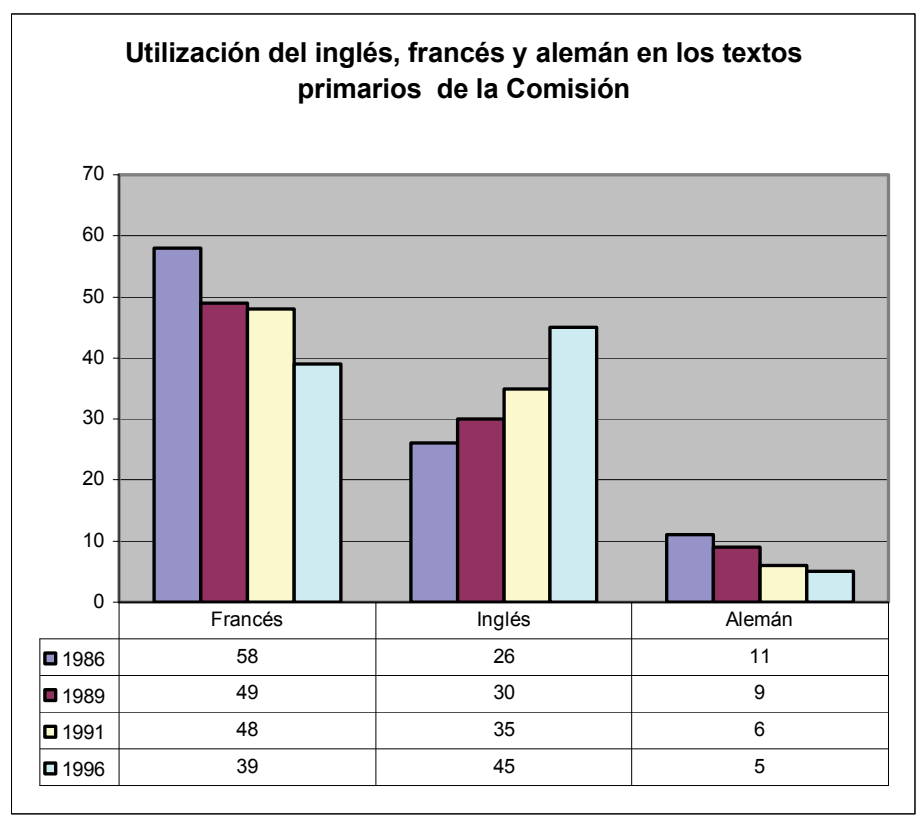

Fuente: Labrie 1993, p. 114; Truchot 2003, p. 104.

Como puede observarse, en 1986, la mayoría de los textos de la Comisión Europea estaban redactados en francés, lo que da una idea de la importancia de esta lengua dentro de la institución. Concretamente, la utilización de esta lengua para la redacción de los documentos que, posteriormente, debían ser traducidos a otras lenguas era en este año más del doble que la del inglés y más de cinco veces superior a la del alemán. Sin embargo, esta situación privilegiada del francés con respecto al inglés y al alemán fue perdiendo terreno en un período de tiempo relativamente corto — de 1986 a 1996-, llegando el inglés a superar al francés en 1996. Por su parte, en ese mismo período, el alemán perdió el reducido porcentaje que tenía en 1986. Esto sugiere que la presión del cambio a favor del inglés y en contra del francés y del alemán era muy fuerte.

En cualquier caso, para confirmar que esta situación no está condicionada por las inercias institucionales — urgencia de la traducción, importancia del documento en cuestión, etc. - sino que obedece a una elección de la lengua por parte de los artífices de esos documentos, es necesario analizar el comportamiento lingüístico de los 
hablantes institucionales. Así, en un estudio empírico publicado en 1991, Jacob Haselhuber realizó un sondeo sobre el conocimiento de segundas lenguas entre 120 licenciados que habían acudido a la Comisión Europea para realizar un curso de formación previo a la incorporación a la plantilla de funcionarios de esta institución. Pues bien, el conocimiento de segundas lenguas por parte de los encuestados era el que se indica en el siguiente gráfico:

\section{GRÁFICO 2.}

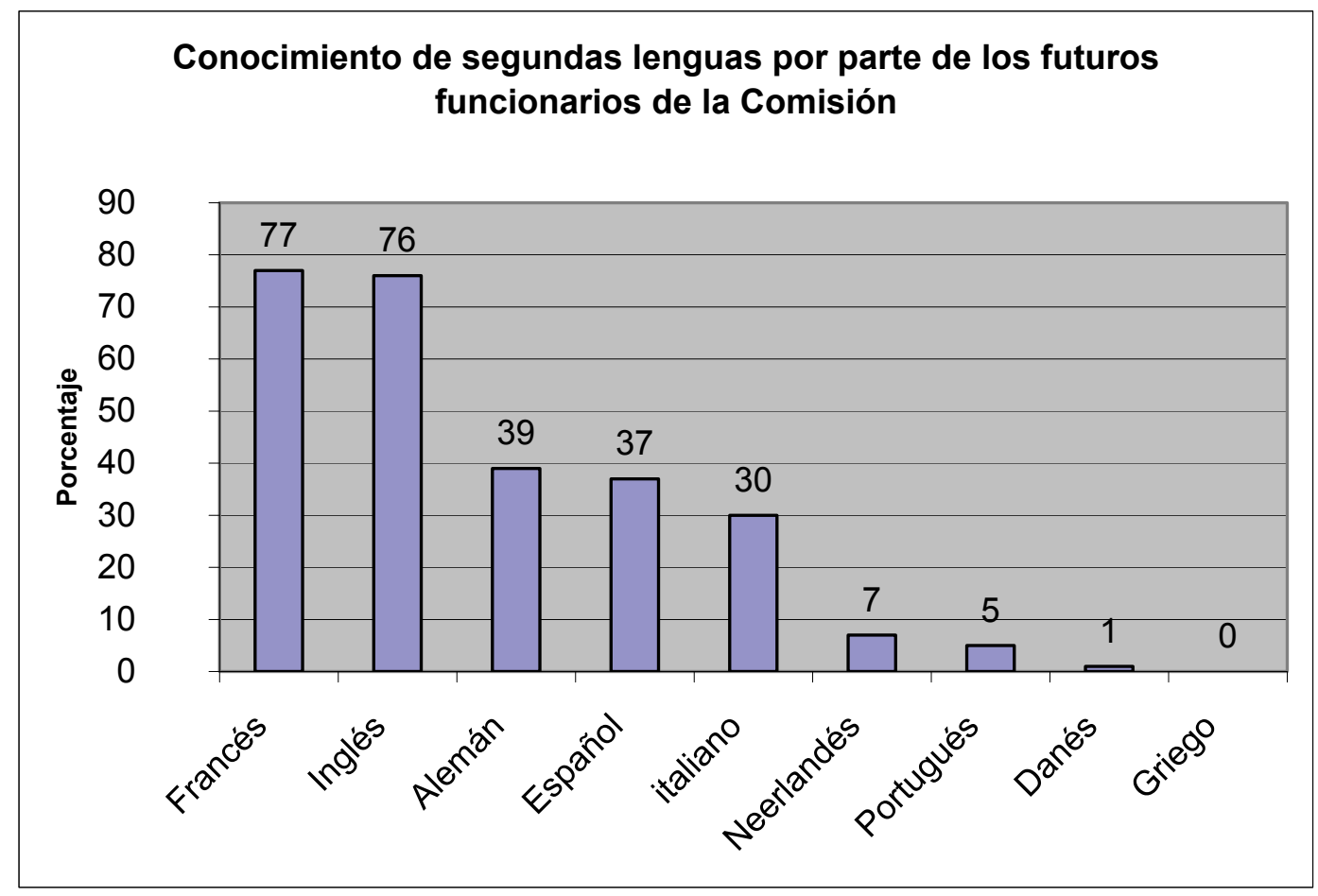

Fuente: Haselhuber 1991, p. $40 .^{5}$

Como se desprende del grafico anterior, el conocimiento de inglés y francés es prácticamente idéntico entre los funcionarios de la Comisión. Por su parte, el conocimiento de alemán, aunque considerable, es sustancialmente inferior con respecto al del inglés o el francés. Esto explica el claro predominio de estas dos lenguas de trabajo en el funcionamiento interno de la Comisión y el papel secundario que representa el alemán.

\footnotetext{
${ }^{5}$ De las cifras absolutas se han obtenido los porcentajes para cada una de las lenguas. Estos porcentajes revelan que una gran parte de los encuestados tiene más de una lengua como segunda lengua.
} 
Sin embargo, esta descripción de un momento concreto en el tiempo - 1990-, si bien indica una práctica de hecho dentro de la Comisión, no es determinante para observar en qué medida esta situación de privilegio de la que disfrutaba el francés estaba en peligro en la época de que se trata. Para ello es necesario recurrir a datos que indiquen tendencias de evolución del uso de las distintas lenguas analizadas. Aunque casi no existen datos que permitan realizar un análisis diacrónico de esta evolución, sí que disponemos de datos relativos a la utilización de las lenguas por parte de los funcionarios de la Comisión en función del grupo de edad al que pertenecen. Así, Gehnen (1991: 60) preguntó a una muestra de funcionarios pertenecientes a la misma categoría sobre las lenguas de trabajo que preferían utilizar. Además, se preocupó de establecer tres grupos de edad distintos - mayores de 50 años, entre 35 y 50 años y menores de 35-. Pues bien, si agregamos los resultados de las respuestas dadas por los encuestados, la situación quedaría reflejada en el siguiente gráfico:

GRÁFICO 3.

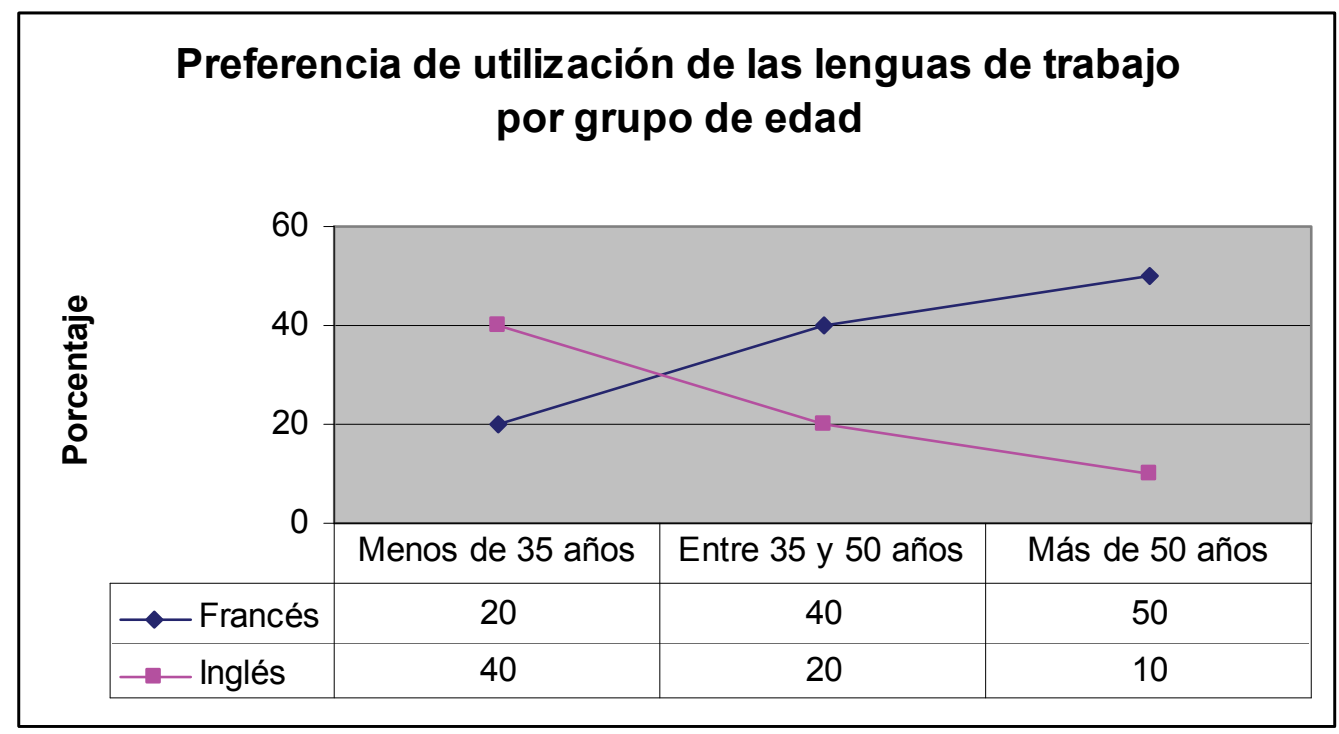

Fuente: Gehnen 1991, p. 60.

Aunque el gráfico describe una situación puntual, al estar los datos desglosados según el grupo de edad, podemos establecer una tendencia válida sobre la evolución futura de las dos lenguas analizadas. Esta tendencia indica que se estaba produciendo un relevo lingüístico en lo que al uso de las lenguas de trabajo se refiere. Es decir, dada la preferencia por utilizar el inglés entre las nuevas generaciones de funcionarios de la Comisión, era de esperar que, a medida que fuera renovándose la plantilla de esta institución, el inglés sustituyera al francés como lengua de trabajo más utilizada. 
Hasta ahora hemos estudiado la posición del inglés, el francés y el alemán como lenguas de trabajo de la UE dentro de las instituciones. Sin embargo, para completar nuestro análisis es preciso conocer cuál era el grado de utilización de estas lenguas de trabajo como lenguas francas de la Unión fuera de las instituciones. En este sentido, el siguiente gráfico intenta describir las tendencias de estas tres lenguas combinando dos elementos. Por una parte, muestra el conocimiento de estas tres lenguas en dos años diferentes - 1987 y 1990 - y, por otra, desglosa dichos datos por grupos de edad para observar si existe un relevo lingüístico generacional. El resultado de la combinación de estos dos elementos es el siguiente:

GRÁFICO $4{ }^{6}$

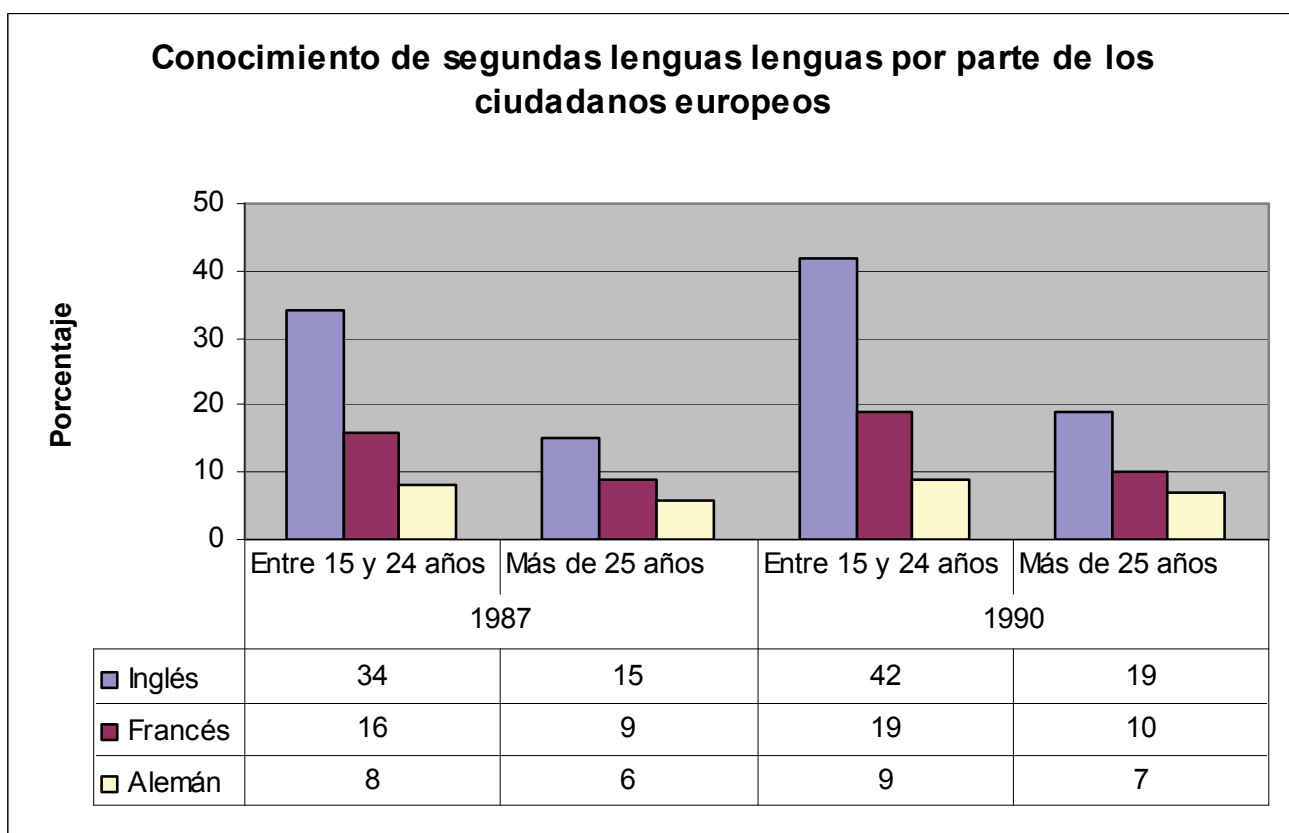

Fuente: Eurobarómetro 34.2, p. 80.

De la interpretación del gráfico anterior pueden extraerse dos conclusiones. En primer lugar, que, en 1990, existía una tendencia al afianzamiento del inglés como lengua franca entre los ciudadanos de la UE. Además, esta tendencia es ya apreciable en un período de tan solo tres años en los dos grupos de edad estudiados, lo que despeja las dudas sobre la evolución futura de esta directriz. En segundo lugar, si atendemos al desglose en función de la edad, podemos observar que se estaba produciendo un relevo lingüístico entre las tres lenguas analizadas. Esto es así porque las nuevas generaciones apuestan claramente por el aprendizaje del inglés en lugar del francés o el alemán. De este modo, el desglose por grupos de edad nos permite

\footnotetext{
${ }^{6}$ Elaboración propia a partir de datos ofrecidos en Eurobarómetro 34.2, p. 80.
} 
afirmar que existe una segunda tendencia: a la consolidación del inglés como lengua franca en el ámbito extrainstitucional de la UE. La combinación de estas dos tendencias dibuja, por tanto, un escenario de desplazamiento progresivo del francés como lengua de comunicación supranacional.

Dado que todas las tendencias apuntaban a una pérdida de representatividad del francés en un futuro no muy lejano, los franceses se enfrentaban a un dilema: o continuaban con la misma estrategia de pasividad, que tendría como resultado la más que probable pérdida del protagonismo de su lengua o, por el contrario, diseñaban una nueva estrategia para intentar recuperar el terreno perdido o, al menos, conservar el que les quedaba.

\section{La diversidad lingüística como instrumento de defensa del francés.}

A pesar del progresivo deterioro de la situación privilegiada del francés en la UE, esta no resultó crítica hasta 1992, que representa el punto de inflexión a partir del cual el francés comenzó a ceder el testigo al inglés como lengua franca principal de la UE. Esta situación crítica motivó el diseño de una estrategia urgente que acudiera en auxilio del francés y que estuviera basada en la promoción conjunta del francés y del plurilingüismo (Michel 2005). El objetivo de esta política era poner coto a una situación de riesgo para el francés y el resto de las lenguas que se ha identificado claramente en diversos documentos institucionales franceses. Así, la DGLF se expresa en los siguientes términos:

La politique en faveur de la langue française et du plurilinguisme repose sur la conviction que pratiquer une seule langue, à l'échelle de la planète, conduirait à une dommageable uniformisation de la pensée, tandis que préserver le multilinguisme - chaque langue portant en elle une vision du monde - garantit au contraire la pluralité des points de vue et des expressions. À cet égard, la défense de la langue française et l'ouverture aux autres langues font système: c'est en permettant à nos concitoyens d'être bien dans leur langue, que nous les persuaderons de s'ouvrir plus largement encore aux langues des «autres»; à l'inverse, la pratique des autres langues peut « décomplexer» l'usage du français. (DGLFLF 2007: 11). ${ }^{7}$

Esta visión uniformizadora que supone el uso de una sola lengua a escala mundial y la medicina de la diversidad lingüística como única herramienta válida para combatir esta enfermedad también ha sido expresada por Chirac en algunos de sus discursos:

Une langue, c'est d'abord une ouverture sur une autre culture. Et donc une autre vision des choses. De ce point de vue, c'est très important. Même des langues qui apparaissent peu parlées,

\footnotetext{
${ }^{7}$ La política en favor de la lengua francesa y del plurilingüismo se basa en la creencia de que practicar una sola lengua a escala mundial daría lugar a una uniformización perjudicial del pensamiento, mientras que preservar el multilingüismo - dado que cada idioma comporta una visión del mundoasegura lo contrario: la pluralidad de puntos de vista y de formas de expresión. En este sentido, la defensa de la lengua francesa y la apertura a otros idiomas se ayudan mutuamente: permitiendo que nuestros ciudadanos se sientan cómodos en su propio idioma, les convenceremos para que se abran aún más a las lenguas de los "otros"; por el contrario, la práctica de otros idiomas puede facilitar el uso del francés. (Traducción DFV).
} 
apportent quelque chose sur le plan culturel. Sur le plan économique, il y a des langues qui sont plus ou moins utiles parce que plus ou moins parlées. Le français est une langue utile. Et rien ne serait pire, je crois, pour l'humanité, que de progresser vers une situation où il y aurait une seule langue. Parce que cela conduit forcément à une espèce de rétrécissement de la pensée. Une langue, c'est également l'expression d'une pensée. Parler tous la même langue, c'est forcément rétrécir la pensée, et cela finirait par avoir des conséquences graves. (Chirac 2004: 2). ${ }^{8}$

Las declaraciones anteriores vienen a hacer explícito el sentimiento de amenaza al que se enfrenta la lengua francesa y que es percibido tanto por el mundo académico (DGLFLF 2007: 11) como por la clase política del país. Esta amenaza ha motivado incluso un debate dentro de las instituciones nacionales galas. Así, en palabras del Ministro de Asuntos Exteriores Francés: Cette place est menacée par les développements de la construction européenne qui tendent à favoriser la pratique du monolinguisme (Respuesta ministerial, 25/10/2005). ${ }^{9}$

Dado que la política de defensa institucional no estaba dando los frutos deseados en el ámbito europeo, los líderes franceses decidieron adoptar una nueva estrategia, que vendría a sumarse a la ya existente. El elemento principal de esta estrategia de promoción del francés como lengua franca de la Unión Europea se basaba en vincular la defensa de la lengua francesa en particular a la defensa de la diversidad lingüística en general (Wright 2006: 44). Tal como se definía desde el propio Ministerio de Cultura francés (Shelly: 1999: 312), los objetivos de la nueva política lingüística de Francia eran tres:

- garantizar la presencia y la influencia del francés.

- mantener su papel como lengua de comunicación internacional y

- preservar la diversidad lingüística y cultural mediante la promoción del multilingüismo.

Es decir, como estrategia para frenar el avance del inglés, Francia se erigía en adalid de la diversidad lingüística y cultural, incluyendo en su estrategia de defensa del francés el respeto y la protección de las lenguas minoritarias. La defensa de estas últimas siempre ha servido de contrapunto a la imagen de uniformización política e ideológica que la incursión del inglés ha representado para los líderes políticos franceses (Pup 2004: 10).

Sin embargo, el diseño y la puesta en marcha de la nueva estrategia francesa no habría sido posible sin la firma del Tratado de Maastricht en 1992, que introdujo en

\footnotetext{
${ }^{8}$ Un idioma es ante todo una apertura a otra cultura. Por tanto, supone otra visión de las cosas. Desde este punto de vista, es algo muy importante. Incluso los idiomas que parecen menos hablados, aportan algo en el ámbito cultural. En el campo económico, hay lenguas que son más o menos útiles, en función de lo que se hablen. El francés es un idioma útil. Y nada podría ser peor, creo yo, para la humanidad, que avanzar hacia una situación en la que hubiera una sola lengua. Porque esto conduce inevitablemente a una especie de estrechamiento del pensamiento. Un idioma es también una expresión del pensamiento. Hablar todos el mismo idioma significa necesariamente limitar el pensamiento, algo que acabaría teniendo graves consecuencias. (Traducción DFV).

9 Esta posición se ve amenazada por la evolución de la construcción europea, que tiende a favorecer la práctica del monolingüismo. (Traducción DFV).
} 
el acervo regulador comunitario el principio de subsidiariedad. Según este principio, la Comunidad solo podría intervenir en la medida en que los objetivos de la acción pretendida no pudieran ser alcanzados de manera suficiente por los Estados miembros, y, por consiguiente, pudieran lograrse mejor, debido a la dimensión o a los efectos de la acción contemplada, a nivel comunitario. En este sentido, su incorporación al ordenamiento jurídico comunitario supuso también una renacionalización de las políticas lingüísticas comunitarias o, si se prefiere, una descentralización de las mismas. En el caso francés, la aplicación de este principio permitió articular una nueva estrategia gala de defensa del francés en la UE en torno a otro de los principios recogidos en el Tratado: la diversidad cultural y lingüística. La combinación de estos dos factores - la defensa de la diversidad y la devolución de poderes a los Estados miembros de la Unión representada por el principio de subsidiariedad - hizo que la nueva estrategia contase con el beneplácito del resto de los Estados miembros.

Con todo, el inicio de esta nueva estrategia no significó un abandono del resto de las políticas de defensa de la lengua francesa ya iniciadas. Más bien al contrario: a las ya existentes se añadieron otras nuevas más encaminadas a conservar el bastión de lengua franca institucional que aun ostentaba el francés. En el marco de estas medidas, se sufragó la financiación de la formación en lengua francesa de los futuros funcionarios europeos procedentes de los distintos Estados miembros. Del mismo modo, se aleccionó a los funcionarios nacionales y, en general, a todos los ciudadanos franceses que utilizan las instituciones comunitarias para que reivindicaran el uso de su lengua nacional en las instituciones de la UE cuando este no estuviera garantizado.

Respecto a los resultados de esta nueva estrategia, aún está pendiente la realización de estudio cuantitativo pormenorizado que arroje algo de luz sobre la evolución del francés con respecto a al inglés y al alemán. Sin embargo, el análisis diacrónico de los datos estadísticos disponibles, muestra que la estrategia francesa no ha sido todo lo exitosa que deseaban los líderes políticos galos. Al menos eso es lo que se desprende del siguiente gráfico, que muestra el grado de conocimiento de alemán, francés e inglés por parte de los ciudadanos europeos: 
GrÁFICo 5.

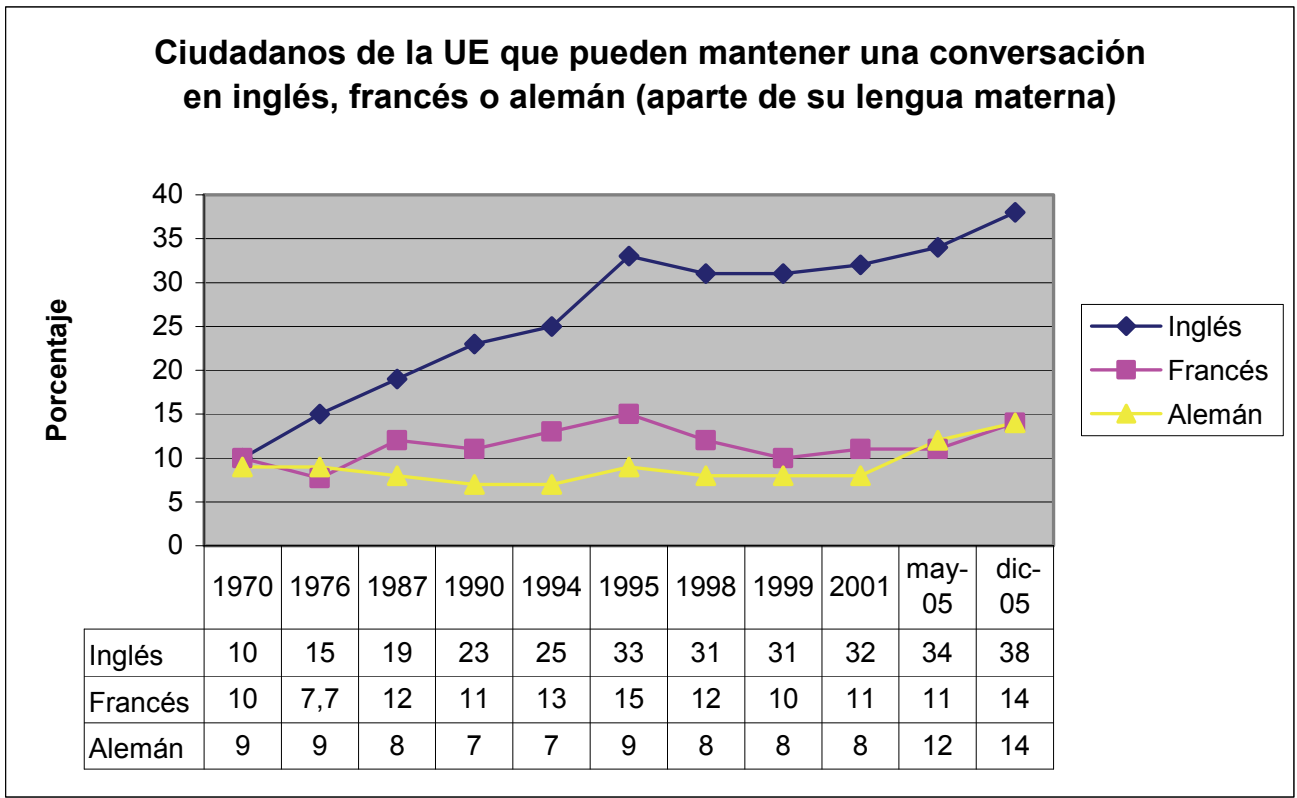

Fuente: elaboración propia a partir de datos recogidos en los Eurobarómetros ${ }^{10}$ y en De Swaan 2001, p. 155.

La principal conclusión que puede extraerse del gráfico es que, en conjunto, desde 1970 ha habido un avance considerable del multilingüismo ${ }^{11}$ en la UE, al menos en lo que a las lenguas más importantes de la Unión se refiere. Es decir, un porcentaje mayor de europeos habla otra lengua aparte de su lengua materna. Sin embargo, este avance del multilingüismo no ha sido igual para las tres lenguas analizadas. De hecho, desde un punto de partida que casi suponía la igualdad numérica de las tres lenguas (10\% de hablantes multilingües para el inglés, $10 \%$ para el francés y $9 \%$ para el alemán) la brecha entre el inglés, por un lado, y el francés y el alemán, por otro, se ha ido abriendo cada vez más. Es decir, este multilingüismo enmascara un avance claro del monolingüismo ${ }^{12}$ en las relaciones supranacionales, ya que la línea descrita por las otras dos lenguas susceptibles de convertirse en lengua franca permanece casi plana en comparación con la del inglés.

${ }^{10}$ Para elaborar el gráfico se han utilizado los Europbarómatros n. ${ }^{\circ} 28$, n. $^{\circ} 34.2$, n. $^{\circ} 38$, n. $^{\circ} 41$, n. ${ }^{\circ}$ 44, n. $^{\circ} 47.2$, n. $^{\circ} 50$, n. $^{\circ} 54.1$, n. $^{\circ} 64.3 / 243$, n. $^{\circ} 52$, n. $^{\circ} 55.1$ y n. ${ }^{\circ} 63.4 / 237$.

${ }^{11}$ El término "multilingüismo" hace referencia tanto a una situación en la que se hablan varias lenguas en una zona geográfica determinada como a la capacidad de una persona para utilizar varios idiomas (HLGM 2007: 6). Dado que es evidente que el multilingüismo en su primer sentido ha aumentado dentro de la UE, al menos en lo relativo a las lenguas oficiales, aquí nos referimos únicamente al segundo sentido.

${ }^{12}$ Entendido, claro está, como herramienta de comunicación supranacional. 
Un dato sin duda llamativo es el repunte que experimenta el inglés en 1995. Aunque el francés y el alemán también experimentan un repunte, su intensidad es mucho menor. Con todo, este aumento del inglés no es excesivamente significativo desde una lógica causal porque se corrige en los siguientes años, también para el francés y el alemán, y porque no existe ningún cambio importante relativo a las políticas lingüísticas que lo motive, salvo el hecho de que, al coincidir con la quinta ampliación de la UE, el entusiasmo de los nuevos miembros o de los antiguos con respecto al proyecto europeo hubiese distorsionado al alza la percepción que estos ciudadanos tenían sobre sus capacidades multilingües individuales. En cualquier caso, una vez superada la resaca de la ampliación, en 1998, la línea recupera la tendencia alcista progresiva iniciada en 1970. Lo importante para el caso que nos ocupa es constatar esta imparable tendencia al alza que experimenta el inglés a lo largo de los años. Tendencia que se mantiene casi imperturbable incluso después de la ampliación de 2004. Esto último sí resulta sorprendente si se tiene en cuenta que, en los nuevos Estados miembros, el idioma que tradicionalmente se ha aprendido como segunda lengua solía ser otro distinto del inglés —alemán (Truchot 2003: 105), ruso, francés - ${ }^{13}$, lo que debería cambiar la tendencia del inglés forzándolo a la baja en lugar de provocar un aumento de dos puntos en su porcentaje, como es el caso entre 2001 y 2005.

\section{Conclusiones.}

De todo lo expuesto anteriormente pueden extraerse varias conclusiones. En primer lugar, el recorrido histórico de la lengua francesa describe el nacimiento y la consolidación del francés como lengua franca de referencia en Europa y en el mundo desde finales del siglo XVII hasta nuestros días. Consecuencia directa de su primacía en Europa en el ámbito económico, cultural y militar, esta posición dominante del francés ha permanecido casi inalterable hasta comienzos del siglo XX. Fue entonces cuando el francés empezó a perder terreno a favor del inglés.

Por otra parte, esta posición dominante a lo largo de los siglos ha tenido como resultado el afianzamiento del francés como lengua de la diplomacia, aún cuando ese idioma ya no ocupaba la posición de lengua franca mundial por excelencia. Esto es evidente en el caso de la Unión Europea, donde el francés ha sido la lengua más utilizada desde la firma de los Tratados de Roma. Sin embargo, en 1973, fecha del ingreso del Reino Unido e Irlanda en la UE, la balanza lingüística comenzó a inclinarse a favor del inglés. Desde entonces y hasta 1992, el uso del inglés experimentó un crecimiento paulatino en detrimento, en gran medida, del francés, cuyo uso no dejaba de reducirse. De hecho, puede afirmarse que, con anterioridad a la entrada en vigor del Tratado de Maastricht y a la introducción del principio de subsidiariedad, en la Comunidad Europea existía un duopolio lingüístico, en lo que a la utilización de lenguas francas se refiere, representado por el inglés y el francés. Así, el inglés era la lengua franca dominante en las comunicaciones supranacionales, mientras

\footnotetext{
${ }^{13}$ Véase Eurobarómetro n. ${ }^{\circ} 63.4$ / 237, p. 5.
} 
que el francés conservaba un bastión institucional en el que su uso como lengua franca era indiscutible.

Sin embargo, existían dos tendencias que apuntaban claramente hacia un avance del inglés en el futuro, en detrimento del francés, en el plano institucional. La primera es la utilización de estas dos lenguas en la redacción de los textos primarios de la Comunidad que, en el caso del francés, no había dejado de perder terreno desde 1986 hasta 1992, fecha de la firma del Tratado de Maastricht. Terreno que había ido ganando, casi proporcionalmente, el inglés. La segunda tendencia es la aportada por el uso que hacen de estas lenguas los funcionarios de las instituciones europeas en función del grupo de edad al que pertenecen. Esta tendencia indica claramente que se estaba produciendo un relevo lingüístico, en lo que al uso de estas lenguas de trabajo se refiere, que beneficiaba claramente al inglés y perjudicaba al francés.

Por último, la firma ese mismo año - 1992 - del Tratado de Maastricht introdujo en el acervo regulador comunitario el principio de subsidiariedad. La aplicación de este principio permitió articular una nueva estrategia francesa de defensa del francés en la UE en torno a otro de los principios recogidos en el Tratado: la diversidad cultural y lingüística. La combinación de estos dos factores - la defensa de la diversidad y la devolución de poderes a los Estados miembros de la Unión representada por el principio de subsidiariedad - hizo que la nueva estrategia contase con el visto bueno del resto de los Estados miembros.

Con todo, los frutos de esta nueva estrategia no están del todo claros. De hecho, a juzgar por el imparable avance de la utilización del inglés como lengua de comunicación supranacional en los años posteriores, dicha estrategia ha sido fallida.

\section{REFERENCIAS BIBLIOGRÁFICAS}

BRAUDEL, F. (1986): L'identité de la France, Vol 2, Artaud, París.

BRUNEAU, Ch. (1966a): Petite histoire de la langue française, Vol. 1, Armand Colin, París.

- (1966b): Petite histoire de la langue française, Vol. 2, Armand Colin, París.

CARRERE D'ENCAUSSE, H. (2002): Au secours du français. Discurso pronunciado en la Séance publique annuelle de la Académie française, (5 diciembre 2002). Disponible en Internet: http://www.academie-

francaise.fr/immortels/discours_spa/carrere2002.html [consulta: 10 Agosto 2008]

COHEN, M. (1973): Histoire d'une langue: le Français (des lointaines origines à nos jours), Éditions Sociales, París.

CHIRAC, J. (2004): Débat de M. Jacques Chirac, Président de la République, avec des jeunes Vietnamiens, sur les relations culturelles entre la France et le Vietnam, l'enseignement du français et des langues étrangères et sur la diversité culturelle, considérée comme un des piliers du développement durable, Hanoï, (7 octubre 2004).

Disponible en Internet: http://www.vie-publique.fr/cdp/047000153.html [consulta: 3 octubre 2008].

DE BERTIER DE SAUVIGNY, G. et ál (1986): Historia de Francia, Madrid, Rialp.

DE SWAAN, A. (2001): Words of the World: The Global Language System, Polity Press, Cambridge. 
DGLFLF [Délégation Générale à la Langue Française et aux Langues de France] (2007): Les politiques des langues en Europe, DGLFLF, París. Disponible en Internet:

http://www.dglf.culture.gouv.fr/publications/politique_langues_europe_2007.pdf

Diario Oficial de las Comunidades Europeas n. ${ }^{\circ} \mathrm{C} 50 / 1$ de 23 febrero de 2002.

Eurobarómetro especial, n. ${ }^{\circ} 54.1$ (febrero 2001): "Europeans and languages". INRA, European Coordination Office, Bruselas. Disponible en Internet:

http://ec.europa.eu/public_opinion/archives/ebs/ebs_147_en.pdf [Consulta: 11 abril 2007].

Eurobarómetro especial, n. ${ }^{\circ}$ 64.3 / 243 (febrero 2006): "Europeans and their languages", Comisión Europea, Bruselas. Disponible en Internet:

http://ec.europa.eu/public_opinion/archives/ebs/ebs_243_en.pdf [Consulta: 13 junio 2008]. Eurobarómetro, n. ${ }^{\circ} 38$, (septiembre 1988). "Young Europeans in 1987”, Comisión Europea, Bruselas. Disponible en Internet:

http://ec.europa.eu/public_opinion/archives/ebs/ebs_38_en.pdf [Consulta: 7 junio 2008].

Eurobarómetro, n. ${ }^{\circ} 28$ (diciembre 1987), Bruselas, Comisión Europea. Disponible en

Internet: http://ec.europa.eu/public_opinion/archives/eb/eb28/eb28_en.pdf [Consulta: 11 noviembre 2008 ].

Eurobarómetro, n. ${ }^{\circ} 34.2$ (mayo 1991). "The Young Europeans in 1990”, Comisión Europea, Bruselas. Disponible en Internet:

http://ec.europa.eu/public_opinion/archives/ebs/ebs_51_en.pdf [Consulta: 16 noviembre 2008].

Eurobarómetro, n. ${ }^{\circ} 41$ (1994), Comisión Europea, Bruselas. Disponible en Internet: http://ec.europa.eu/public_opinion/archives/eb/eb41/eb41_en.pdf [Consulta: 6 junio 2008].

Eurobarómetro, n. ${ }^{\circ} 44$ (1996), Comisión Europea, Bruselas. Disponible en Internet: http://ec.europa.eu/public_opinion/archives/eb/eb44/eb44_en.htm [Consulta: 13 marzo 2008].

Eurobarómetro, n. ${ }^{\circ} 47.2$ (1997), “The Young Europeans”, Comisión Europea, Bruselas. Disponible en Internet: http://ec.europa.eu/public_opinion/archives/ebs/ebs_114_en.pdf [Consulta: 3 marzo 2008].

Eurobarómetro, n. ${ }^{\circ} 50$ (1999), Comisión Europea, Bruselas. Disponible en Internet: http://ec.europa.eu/public_opinion/archives/eb/eb50/eb50_en.pdf [Consulta: 3 enero 2008].

Eurobarómetro, n. ${ }^{\circ} 52$ (2000), Comisión Europea, Bruselas. Disponible en Internet: http://ec.europa.eu/public_opinion/archives/eb/eb52/eb52_en.pdf [Consulta: 3 marzo 2008].

Eurobarómetro, n. $^{\circ} 55$ (octubre 2001), Comisión Europea, Bruselas. Disponible en Internet: http://ec.europa.eu/public_opinion/archives/eb/eb55/eb55_en.pdf [Consulta: 5 febrero 2008].

Eurobarómetro, n. 55.1 (agosto 2001), “Les jeunes europeens en 2001”. INRA, Comisión Europea, Bruselas. Disponible en Internet: http://ec.europa.eu/public_opinion/archives/ebs/ebs_151_fr.pdf [Consulta: 1 marzo 2008].

Eurobarómetro, n. 63.4 / 237 (septiembre 2005), "Europeans and Languages", Comisión Europea, Bruselas. Disponible en Internet: http://ec.europa.eu/public_opinion/archives/ebs/ebs_237.en.pdf [Consulta: 12 enero 2007]. FUMAROLI, M. (2001): Quand L 'Europe parlait français, Fallois, París.

GEHNEN, M. (1991): "Die Arbeitssprachen in der Kommission des Europäischen Gemeinschaft unter besonderer Berücksichtingung des Französischen”, in Sociolinguistica, n. ${ }^{\circ}$ 5, 51-63. 
HAGEGE, C. (1987): Le français et les siècles, Odile Jacob, París.

- (1996): Le français, histoire d'un combat, Michel Hagège, Boulogne-Billancourt.

HASELHUBER, J. (1991): "Erste Ergebnisse einer. empirischen Untersuchung zur Sprachensituation. in der EG-Kommission (Februar 1990)“", in Sociolinguistica, n. ${ }^{\text {o }}$ $5,37-50$.

HLGM [High Level Group on Multilingualism] (2007): Final Report, Comisión Europea, Bélgica. Disponible en Internet:

http://ec.europa.eu/education/policies/lang/doc/multireport_en.pdf [Consulta: 21 diciembre 2008].

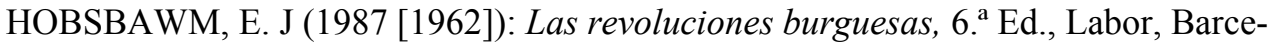
lona.

HOLT, M. (2002): "The French Language: Universalism and Post-colonial Identity", in P. Gubbins y M. Holt (eds.), Beyond boundaries. Language and identity in contemporary Europe, Multilingual Matters, Clevedon, 101-10.

LONGMAN, C. (2007): "English as a Lingua Franca: a Challenge to the Doctrine of Multilingualism", in D. Castiglione y C. Longman (eds.) The Language Question in Europe and Diverse Societies: Political, Legal and Social Perspectives. 2007, Hart Publishing, Oxford; Portland, 185-215.

MICHEL, J. (2005): Pregunta parlamentaria n. ${ }^{\circ} 66714$ sobre la influencia creciente del inglés en las instituciones europeas, ( 7 junio 2005). Disponible en Internet:

http://www.langue-francaise.org/Textes_politiques/Michel_07_06_2005_66714.php [consulta: 10 Junio 2008].

OGG, D. (1987 [1967]): La Europa del Antiguo Régimen 1715-1789, 6. ${ }^{\mathrm{a}}$ Ed., Siglo Veintiuno Editores, Madrid.

PHILLIPSON, R. (2003): English-only Europe? Challenging language policy, Routledge, Londres.

PUP, H. del (2004): "Statut de la langue française et des autres langues en France", in Dialogues Politiques, n. ${ }^{\circ}$ 2. Disponible en Internet: http://www.la-sciencepolitique.com/revue/revue2/papier8.htm.

Respuesta ministerial a la pregunta parlamentaria $n .{ }^{\circ} 66714$ sobre la influencia creciente del inglés en las instituciones europeas, (25 octubre 2005). Disponible en Internet: http://www.langue-francaise.org/Textes_politiques/Michel_07_06_2005_66714.php [consulta: 10 Junio 2008].

SAINT-PROSPER, A. J. C. (1840): Historia de Francia, desde los tiempos más remotos hasta 1839, Vol. 1, Imprenta Brusi, Barcelona.

SÁNCHEZ ANDRÉS, A. (2003): "Nacionalismo y Relaciones Internacionales. El surgimiento de las nuevas potencias europeas continentales y la quiebra del concierto europeo, 1848-1871", in J. C. Pereira (Coord.) Historia de las relaciones internacionales contemporáneas, Ariel, Barcelona, 153-168.

SHELLY, S. L. (1999): "Une certaine idee du francais: The dilemma for French language policy in the 21st century", in Language and Communication, n. ${ }^{\circ} 19,305-316$.

TRUCHOT, C. (2001): "The languages of sciences in France: Public Debate and Language Policies", in U. Ammon (ed.) The dominance of English as a Language of Science: Effects on other Languages and Language Communities, Mouton de Gruyter, Berlín, 319-328. 
- (2003): "Languages and Supranationality in Europe: The Linguistic Influence of the European Union”, in J. Maurais (ed.) Languages in a Globalising World, Nueva York, Cambridge University Press, 99-110.

WRIGHT, G. (2004): “Cyprus Split on Annan Plan”, in The Guardian (23 abril 2004). Disponible en Internet:

http://www.guardian.co.uk/cyprus/story/0,11551,1202077,00.html [consulta: 22 junio 2004].

- (2006): "French as a Lingua Franca", in Annual Review of Applied Linguistics 26, 35-60. 